\title{
Genetic and molecular alterations associated with oral squamous cell cancer (Review)
}

\author{
MARIO PÉREZ-SAYÁNS ${ }^{1}$, JOSÉ MANUEL SOMOZA-MARTÍN ${ }^{1}$, FRANCISCO BARROS-ANGUEIRA ${ }^{2}$, \\ MARÍA DOLORES REBOIRAS-LÓPEZ ${ }^{1}$, JOSÉ MANUEL GÁNDARA REY ${ }^{1}$ and ABEL GARCÍA-GARCÍA ${ }^{1}$ \\ ${ }^{1}$ Facultad de Odontología, Entrerríos s/n, Santiago de Compostela, C.P. $15782 ;{ }^{2}$ Unity of Molecular Medicine, Fundación \\ Pública Galega de Medicina Xenómica, Hospital Clinico Universitario, Santiago de Compostela, C.P. 15706, Spain
}

Received July 6, 2009; Accepted August 10, 2009

DOI: $10.3892 /$ or_00000565

\begin{abstract}
The development of oral squamous cell cancer (OSCC) is a multistep process involving the accumulation of multiple genetic alterations modulated by genetic predisposition and environmental influences such as tobacco and alcohol use, chronic inflammation, and viral infections. All of these factors can lead to a wide range of genetic and molecular alterations that can be detected using a range of molecular studies. The alterations mostly affect two large groups of genes: oncogenes and tumor suppressor genes, which can be either inactivated or overexpressed through mutations, loss of heterozygosity, deletions, or epigenetic modifications such as methylation. Other molecules that are closely associated with tumor pathogenesis and prognosis also exist and warrant further study. Important advances in molecular biology are helping to shed light on oral cancer and thus aiding in the early diagnosis and development of new personalized treatment approaches. The purpose of the review is to explore the genetic and molecular alterations associated with OSCC.
\end{abstract}

\section{Contents}

1. Introduction

2. Differential gene expression in oral squamous cell carcinoma

3. Genetic and epigenetic anomalies in OSCC

4. Other molecules associated with OSCC

5. Conclusions

\section{Introduction}

Oral squamous cell carcinoma (OSCC) is the most common malignancy of the oral cavity. Accounting for between 90 and $95 \%$ of all malignant lesions of the mouth, OSCC

Correspondence to: Dr Mario Pérez-Sayáns, Facultad de Odontología, Entrerríos s/n, Santiago de Compostela, C.P. 15782, Spain

E-mail: perezsayans@gmail.com

Key words: oncogenes, tumor suppressor genes, oral squamous cell carcinoma, methylation has become practically synonymous with oral cancer. Based on statistics from June 24, 2008, the American Cancer Society reported that $1,437,181$ new cancer cases and 565650 cancerrelated deaths were expected in the United States in 2008 (1). The estimated number of cases of oral cavity cancers was 22,900 , equivalent to $3 \%$ all cancer cases.

Carcinogenesis is a multistep process modulated by both environmental and genetic factors (Fig. 1). As early as 1988, Boyd and Reade (2) described the different mechanisms involved in carcinogenesis of the oral mucosa and distinguished between 2 major groups: chemical mechanisms, physical mechanisms, and viral mechanisms (2). More than a decade later, Hanahan and Weinberg (3) described 6 hallmarks of cancer: acquisition of growth signaling autonomy (oncogenes), growth-inhibitory signals (tumor suppressor genes), evasion of apoptosis, cellular immortalization, angiogenesis, and finally, invasion and metastasis.

\section{Differential gene expression in oral squamous cell carcinoma}

Numerous methods are available for directly analyzing tumor DNA, either directly in the tumor tissue itself or in previously prepared tissue. The most common methods are in situ hybridization, Southern and Northern blot analysis, polymerase chain reaction (PCR), and automatic DNA sequencing. Microarray technology, for its part, is particularly useful for establishing general gene expression patterns and for screening for differential gene expression. Array results, however, need to be validated using an alternative method such as Northern blot analysis or quantitative real-time (RT) PCR, used to evaluate product accumulation during the log phase of the reaction. Quantitative RT-PCR, currently considered the most reliable and reproducible gene quantification method available, is the most widely used technique for validating gene expression results obtained using microarray technology (5-7). To determine gene expression in OSCC, many researchers have combined DNA microarray hybridization with other molecular methods (such as quantitative RT-PCR) that measure differential gene expression.

A large number of studies have used DNA microarray technology to profile gene expression patterns in head and neck cancer and in OSCC in particular (8-29). The majority of these studies have concluded that there is a possible association between different genes and squamous cell 


\section{Normal} oral mucosa
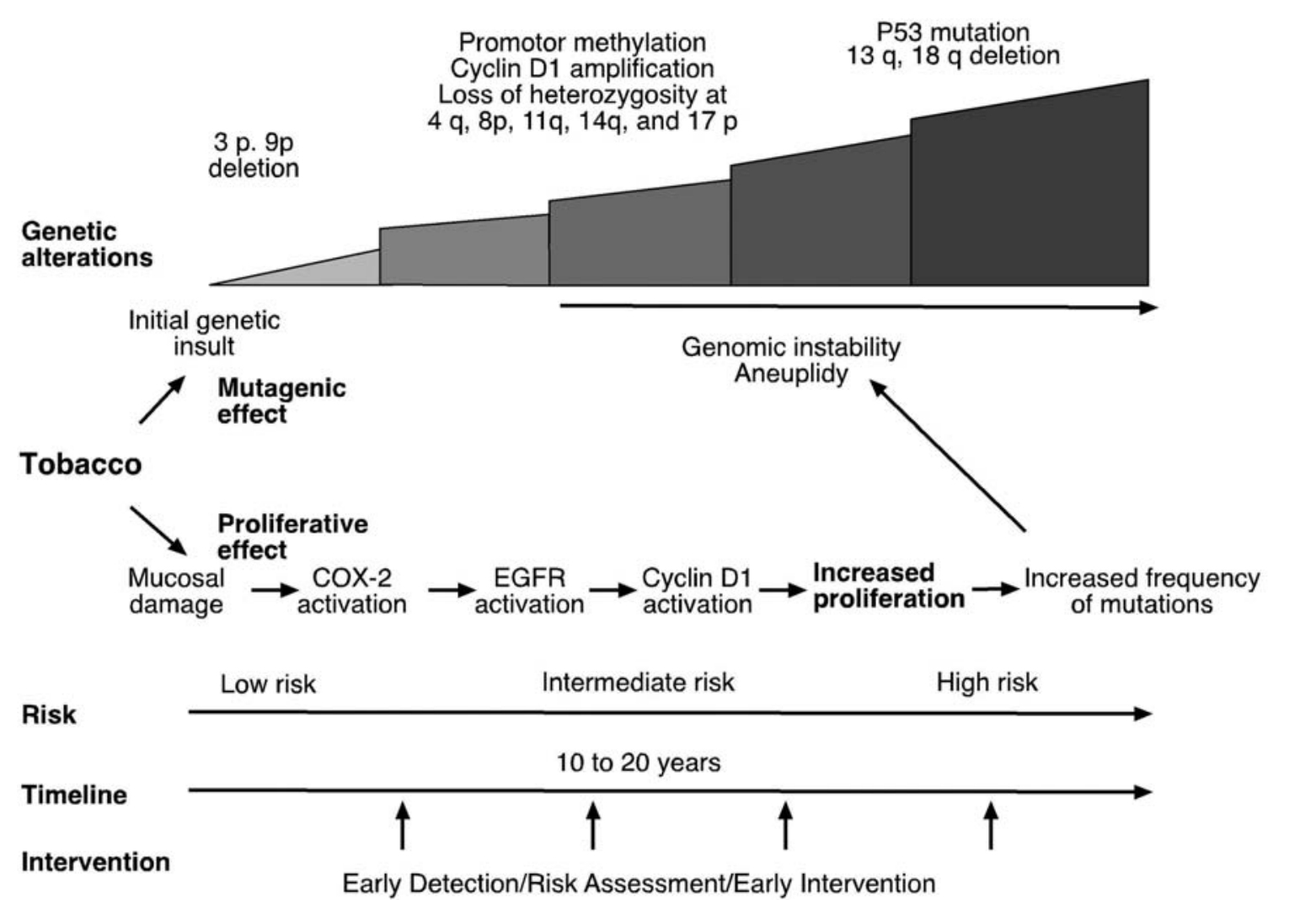

Figure 1. Chronic exposure to carcinogens such as tobacco causes genetic changes in the epithelial cells of the oral mucosa. The accumulation of genetic insults leads to genomic instability, the development of premalignant lesions, and ultimately invasive carcinoma. Carcinogens also have parallel indirect effects such as the induction of proliferative activity through, for example, the epidermal growth factor receptor (EGFR). COX, cyclooxygenase; RAR, retinoic acid receptor. Obtained from (18).

carcinoma. Many of the genes implicated have been previously described and are well known, but others have an unknown biological function and have yet to be analyzed in depth. Based on the results of these microarray studies, these new genes can now be investigated individually to determine their nature and function.

In a relatively recent study, our research group studied gene expression profiles in 5 patients with OSCC using the Atlas Glass Human 3.8 I Microarray (Fig. 2) (30). This microarray consists of 3,888 spots, including 3,757 oligonucleotides, 9 house-keeping genes, and controls. The genes, all well known and characterized, have a wide range of biological functions. Statically significant differences were found between tumor tissue and normal tissue for 426 genes, $322(75.58 \%)$ of which were overexpressed and $104(24.41 \%)$ of which were under-expressed. Interestingly, while the genes found to be differentially expressed varied to some extent between analyses, the biological functions they encoded were identical (Table I) (30).

\section{Genetic and epigenetic anomalies in OSCC}

To facilitate comprehension, we have classified the genetic and epigenetic anomalies associated with OSCC according to the type of structure affected (chromosome, allele, onco- gene, tumor suppressor gene, or nucleotide) and the type of anomaly (polymorphism, point mutation, deletion, and other alterations).

There are reports of frequent chromosomal aberrations (deletions) at 2q21-24, 2q33-35, and 2q37 which affect numerous tumor suppressor genes including $L R P 1 B, C A S P 8$, CASP10, BARD1, ILKAP, PPPIR7, and ING5 (31). One recent study reported that the loss of alleles 3 p14 and $9 \mathrm{p} 21$ occurs early on in the development of OSCC tumors and can even occur in simple keratosis (32). Polysomy 3, for its part, is more common than polysomy 9 and is characteristic of dysplasia and in situ carcinoma (33).

A high frequency of loss of heterozygosity $(\mathrm{LOH})$ at chromosomal loci $13 \mathrm{q}$ and $17 \mathrm{p}$ has been described in premalignant oral lesions and early carcinomas (34). The affected regions harbor important genes whose suppressor function in the development of tumors is probably severely altered by this LOH. Chromosome 9 appears to be one of the regions that is altered most often and earliest in tumor development; allelic losses at 9p21, for example, have been described in the majority of premalignant oral lesions and early carcinomas (Fig. 3) (35).

The $9 \mathrm{p} 21$ region harbors genes that code for the cyclindependent kinase inhibitors p16 and p14, two important regulators of cell proliferation. Several regions of chromo- 
EXPERIMENT_DEMO vs CONTROL. AVERAGE VALUES (SD2)

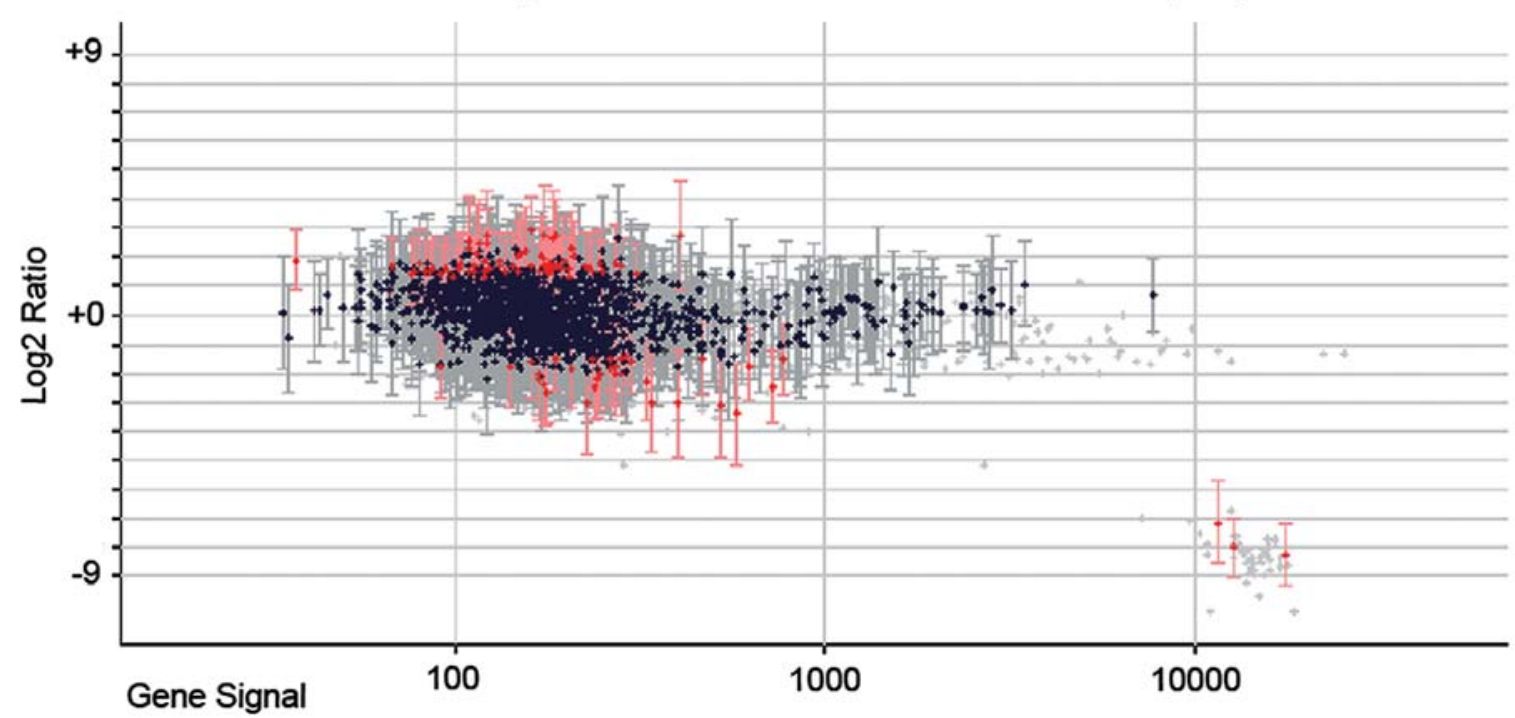

Figure 2. Log2 graph showing Cy3/Cy5 ratio (after normalization of data using the Lowess method) and signal intensity of each microarray spot. The red dots (426 genes and 86 controls) correspond to significantly differentially expressed genes ( $\mathrm{P}=0.05$, t-test) in tumor tissue compared to normal tissue. The vertical bars show the standard deviation. Obtained from (29).

Table I. Number and percentages of genes in each functional category showing significant differences in expression (t-tests, $\mathrm{p}<0.05)$ between normal and tumoral tissue.

Function

Total no. \% Total

No.up- \% up- No.down- \% downregulated regulated regulated regulated

\section{Cell surface antigens}

Transcription factors

Cell cycle proteins

Cell adhesion receptors/proteins

Immune system proteins

Extracellular transport/carrier proteins

Oncogenes and tumor suppressors

Stress response proteins

Membrane channels and transporters

Extracellular matrix proteins

Trafficking/targeting proteins

Metabolism proteins

Post-translational modification/protein folding

Translation

Apoptosis associated proteins

RNA processing, turnover, and transport

DNA binding and chromatin proteins

Cell receptors

Cell signaling, extracellular communication proteins

Intracellular transducers/effectors/modulators

Protein turnover

Cytoskeleton/motility proteins

DNA synthesis, recombination, and repair

Functionally unclassified

\begin{tabular}{|c|c|c|c|c|c|}
\hline 8 & 1.87 & 5 & 1.55 & 3 & 2.88 \\
\hline 52 & 12.20 & 33 & 10.24 & 19 & 18.26 \\
\hline 3 & 0.70 & 3 & 0.93 & 0 & 0 \\
\hline 22 & 5.16 & 19 & 5.90 & 3 & 2.88 \\
\hline 8 & 1.87 & 5 & 1.55 & 3 & 2.88 \\
\hline 17 & 3.99 & 11 & 3.41 & 6 & 5.76 \\
\hline 11 & 2.58 & 8 & 2.48 & 3 & 2.88 \\
\hline 14 & 3.28 & 10 & 3.10 & 4 & 3.84 \\
\hline 27 & 6.33 & 19 & 5.90 & 8 & 7.69 \\
\hline 8 & 1.87 & 5 & 1.55 & 3 & 2.88 \\
\hline 39 & 9.15 & 28 & 8.69 & 11 & 10.57 \\
\hline 80 & 18.77 & 68 & 21.11 & 12 & 11.53 \\
\hline 18 & 4.22 & 13 & 4.03 & 5 & 4.80 \\
\hline 26 & 6.10 & 17 & 5.27 & 9 & 8.65 \\
\hline 6 & 1.40 & 4 & 1.24 & 2 & 1.92 \\
\hline 11 & 2.58 & 11 & 3.41 & 0 & 0 \\
\hline 5 & 1.17 & 4 & 1.24 & 1 & 0.96 \\
\hline 38 & 8.92 & 33 & 10.24 & 3 & 2.88 \\
\hline 19 & 4.46 & 14 & 4.34 & 5 & 4.80 \\
\hline 53 & 12.44 & 36 & 11.18 & 17 & 16.34 \\
\hline 22 & 5.16 & 15 & 4.65 & 7 & 6.73 \\
\hline 25 & 5.86 & 22 & 6.83 & 3 & 2.88 \\
\hline 11 & 2.58 & 5 & 1.55 & 6 & 5.76 \\
\hline 17 & 3.99 & 14 & 4.34 & 3 & 2.88 \\
\hline
\end{tabular}

Obtained from (30). 

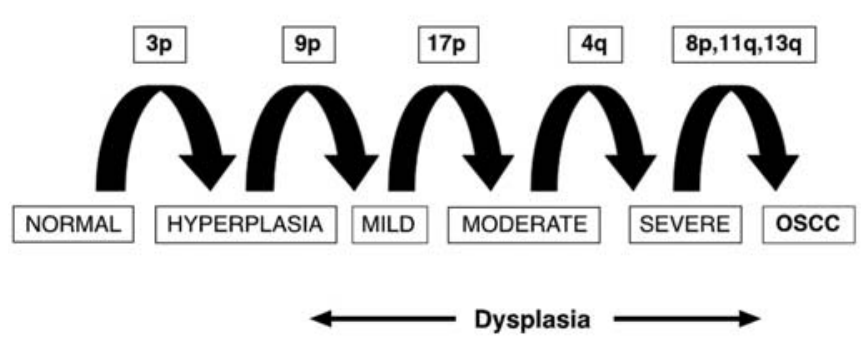

Figure 3. Molecular model of oral carcinogenesis. The diagram shows the genetic progression from dysplasia to oral squamous cell carcinoma (OSCC), through changes in the p or q arm of chromosomes $3,4,8,9$, 11,13 , and 17. Adapted from (64).

some 3, in particular 3p25, 3p21, and 3p13-14, commonly harbor chromosomal aberrations in oral cancer, although it is not yet known which genes are affected (36). Other aberrations such as allelic losses at 5q21-22, 22q13, 4q, 11q, $18 \mathrm{q}$, and $21 \mathrm{q}$, are often found in association with advanced tumor stages and poorly differentiated carcinomas (37).

Recent studies have identified allelic polymorphisms in the genes HLA and MICA (major histocompatibility complex-class-I-chain-related gene A) (38). In one of these studies, HLA-B35 and HLA-B40 were strongly associated with tumor metastasis (39).

Anomalies in certain oncogenes such as ErbBl (Her-1), $\operatorname{ErbB} 2$, and $N$-, $K$ - and $H$-ras have not been found to play a key role in oral cancer (40-43). When altered, genes that code for the synthesis of cyclin proteins, may act as oncogenes. Overexpression of $C C N D 1$, for example, can induce overexpression of the cyclin D1 protein, which has been associated with poor prognosis in early-stage oral tumors (44-46).

Tumor suppressor gene anomalies are also found in malignant oral lesions. Most oral carcinomas are characterized by aberrant expression of at least one of the members of the retinomablastoma $(\mathrm{pRb})$ family of growth suppressor proteins. $C D K N 2 A$, for example, which encodes the protein $\mathrm{p} 16$, is located at locus $9 \mathrm{p} 21$, one of the most vulnerable areas of the human genome in oral cancer, while p14, the alternative transcript of the same gene, is frequently deleted in malignant oral lesions. One of the most important tumor suppressor genes in humans is TP53 (47). The functions of this gene and its molecular system have been found to be suppressed in numerous tumors, constituting one of the earliest findings in the natural history of oral cancer $(48,49)$.

Three single nucleotide polymorphisms detected in the promoter region of the DNMT3B gene-C46359T [-149C $>\mathrm{T}]$, $-238 \mathrm{~T}>\mathrm{C}$, and $-579>\mathrm{T}$-might play a causative role in several cancers, including OSCC (50).

In contrast, in OSCC, the base excision repair pathway, which comprises the genes MUTYH, OGG1, and MTHI and which repairs mutations that involve 8-oxoguanine, has been seen to play a very small or possibly even non-existent role in tumor development (51). Similar findings have been reported following argyrophilic nucleolar organizer region (AgNOR) analyses, although the results have been disputed (18). According to Teresa et al and Costa et al AgNOR and $\mathrm{Ki}-67$ analyses can be used to determine proliferative states of epithelial cells in oral cancer $(39,52)$, and Schwartz et al have shown levels of proliferating cell nuclear antigen to be increased in an experimental model (53).

Our research group found a very interesting association between OSCC and overexpression of ATP6V1C1 54, which seems to be the main gene involved in the regulation of V-ATPase enzymes and the acidity of solid oral tumors (54).

The most common epigenetic alteration is DNA methylation. Imai et al (55) recently demonstrated that Ras association family genes (RASSF) were altered in OSCC. In particular, they found RASSF 2 to be methylated in $26 \%$ of OSCC tumors analyzed (55).

\section{Other molecules associated with OSCC}

Other molecules that have been associated with OSCC are cyclo-oxygenase 2 (COX-2), which has been found in high levels in dysplastic lesions (56); the human trophoblast cell-surface antigen (TROP2), which appears to be associated with shorter survival (57); and the epithelial adhesion molecule (EpCAM), which has been associated with tumor size, regional lymph node metastasis, histologic differentiation, and an invasive pattern (31). The connective tissue growth factor, CCN2 (also known as CTGF), was recently associated with head and neck squamous cell cancer; findings included high levels of messenger RNA (mRNA) and its protein in stromal fibroblasts, tumor cells, and vascular endothelial cells (58). Overexpression of $M M P-2$ and $M M P-9$ has been associated with the invasive potential of tumors and levels of alcohol, leading several authors to hypothesize that alcohol might play a role in oral carcinogenesis through the stimulation of these genes (37).

It has been shown that molecular analysis of saliva can be used to study genomic DNA expression but not mRNA expression (59). Other studies have detected the soluble fragment of cytokeratin 19, Cyfra 21-1, in patients with OSCC, although further studies are required to determine the true diagnostic and prognostic value of this marker $(60,61)$. Recent studies have shown that the determination of proteins and oxidated DNA levels in saliva might indicate high levels of reactive oxygen species, which appear to be involved in the development of OSCC (62).

Other recent findings in this area include the observation of an association between oral cancer and a set of new molecules called advanced glycation endproducts (AGEs) and their receptors (RAGEs) (63). According to the authors of the study, RAGE expression decreases with an increase in OSCC differentiation. RAGEs, for example, are expressed in $100 \%$ of normal epithelial cells but in $0 \%$ of poorly differentiated OSCC cells.

\section{Conclusions}

Oral carcinogenesis is a multifactorial process involving numerous genetic processes that can alter the function of oncogenes, tumor suppressor genes, and other related molecules. The resulting anomalies can increase the production of growth factors and the number of cell surface receptors, and/or increase transcription or intracellular messenger factor levels. These changes can, in turn, cause a loss of tumor 
suppressor activity and give rise to a phenotype capable of increasing cellular proliferation, weakening cell cohesion, and causing local infiltration and metastasis.

\section{References}

1. Jemal A, Siegel R, Ward E, et al: Cancer Statistics. CA Cancer J Clin 58: 71-96, 2008

2. Boyd NM and Reade PC: Mechanisms of carcinogenesis with particular reference to the oral mucosa. J Oral Pathol 17: 193-201, 1988.

3. Hanahan D and Weinberg RA: The hallmarks of cancer. Cell 100: $57-70,2000$

4. Duggan DJ, Bittner M, Chen Y, et al: Expression profiling using cDNA microarrays. Nat Genet 21: 10-14, 1999.

5. Rajeevan MS, Vernon SD, Taysavang N, et al: Validation of array-based gene expression profiles by real-time (kinetic) RT-PCR. J Mol Diagn 3: 26-31, 2001.

6. Higuchi R, Fockler C, Dollinger G and Watson R: Kinetic PCR analysis: real-time monitoring of DNA amplification reactions. Biotechnology (NY) 11: 1026-1030, 1993

7. Wittwer CT, Herrmann MG, Moss AA and Rasmussen RP Continuous fluorescence monitoring of rapid cycle DNA amplification. Biotechniques 22: 130-131, 134-138, 1997.

8. Alevizos I, Mahadevappa M, Zhang X, et al: Oral cancer in vivo gene expression profiling assisted by laser capture microdissection and microarray analysis. Oncogene 20: 6196-6204, 2001.

9. Al Moustafa AE, Alaoui-Jamali MA, Batist G, et al: Identification of genes associated with head and neck carcinogenesis by cDNA microarray comparison between matched primary normal epithelial and squamous carcinoma cells. Oncogene 21: 2634-2640, 2002.

10. Francioso F, Carinci F, Tosi L, et al: Identification of differentially expressed genes in human salivary gland tumors by DNA microarrays. Mol Cancer Ther 1: 533-538, 2002.

11. Hartmann KA, Modlich O, Prisack HB, et al: Gene expression profiling of advanced head and neck squamous cell carcinomas and two squamous cell carcinoma cell lines under radio/chemotherapy using cDNA arrays. Radiother Oncol 63: 309-320, 2002 .

12. Zhang X, Liu Y, Gilcrease MZ, Yuan, et al: A lymph node metastatic mouse model reveals alterations of metastasis-related gene expression in metastatic human oral carcinoma sublines selected from a poorly metastatic parental cell line. Cancer 95: 1663-1672, 2002.

13. Mendez E, Cheng C, Farwell DG, et al: Transcriptional expression profiles of oral squamous cell carcinomas. Cancer 95: 1482-1494, 2002.

14. Ibrahim SO, Aarsaether N, Holsve MK, et al: Gene expression profile in oral squamous cell carcinomas and matching normal oral mucosal tissues from black Africans and white Caucasians: the case of the Sudan vs. Norway. Oral Oncol 39: 37-48, 2003

15. Kuo WP, Hasina R, Ohno-Machado L and Lingen MW: Classification and identification of genes associated with oral cancer based on gene expression profiles. A preliminary study. N Y State Dent J 69: 23-26, 2003.

16. Hwang D, Alevizos I, Schmitt WA, et al: Genomic dissection for characterization of cancerous oral epithelium tissues using transcription profiling. Oral Oncol 39: 259-268, 2003

17. Nagata M, Fujita $\mathrm{H}$, Ida $\mathrm{H}$, et al: Identification of potential biomarkers of lymph node metastasis in oral squamous cell carcinoma by cDNA microarray analysis. Int J Cancer 106 : 683-689, 2003

18. Brinkman BM and Wong DT: Disease mechanism and biomarkers of oral squamous cell carcinoma. Curr Opin Oncol 18: 228-233, 2006.

19. Ziober AF, Patel KR, Alawi F, et al: Identification of a gene signature for rapid screening of oral squamous cell carcinoma. Clin Cancer Res 12: 5960-5971, 2006.

20. Nguyen ST, Hasegawa S, Tsuda H, et al: Identification of a predictive gene expression signature of cervical lymph node metastasis in oral squamous cell carcinoma. Cancer Sci 98: 740-746, 2007.

21. Martinez I, Wang J, Hobson KF, et al: Identification of differentially expressed genes in HPV-positive and HPV-negative oropharyngeal squamous cell carcinomas. Eur J Cancer 43: 415-432, 2007
22. Chang JT, Wang HM, Chang KW, et al: Identification of differentially expressed genes in oral squamous cell carcinoma (OSCC): overexpression of NPM, CDK1 and NDRG1 and underexpression of CHES1. Int J Cancer 114: 942-949, 2005.

23. Arora S, Matta A, Shukla NK, et al: Identification of differentially expressed genes in oral squamous cell carcinoma. Mol Carcinog 42: 97-108, 2005

24. Jeon GA, Lee JS, Patel V, et al: Global gene expression profiles of human head and neck squamous carcinoma cell lines. Int J Cancer 112: 249-258, 2004

25. Ginos MA, Page GP, Michalowicz BS, et al: Identification of a gene expression signature associated with recurrent disease in squamous cell carcinoma of the head and neck. Cancer Res 64: $55-63,2004$

26. Gonzalez HE, Gujrati M, Frederick M, et al: Identification of 9 genes differentially expressed in head and neck squamous cell carcinoma. Arch Otolaryngol Head Neck Surg 129: 754-759, 2003.

27. Leethanakul C, Knezevic V, Patel V, et al: Gene discovery in oral squamous cell carcinoma through the Head and Neck Cancer Genome Anatomy Project: confirmation by microarray analysis. Oral Oncol 39: 248-258, 2003.

28. Steinau M, Lee DR, Rajeevan MS, et al: Gene expression profile of cervical tissue compared to exfoliated cells: impact on biomarker discovery. BMC Genomics 6: 64, 2005.

29. Choi S and Myers JN: Molecular pathogenesis of oral squamous cell carcinoma: implications for therapy. J Dent Res 87: 14-32, 2008.

30. Somoza-Martin JM, Garcia-Garcia A, Barros-Angueira F, et al: Gene expression profile in oral squamous cell carcinoma: a pilot study. J Oral Maxillofac Surg 63: 786-792, 2005.

31. Yanamoto S, Kawasaki G, Yoshitomi I, et al: Clinicopathologic significance of EpCAM expression in squamous cell carcinoma of the tongue and its possibility as a potential target for tongue cancer gene therapy. Oral Oncol 43: 869-877, 2007.

32. Uzawa N, Akanuma D, Negishi A, et al: Homozygous deletions on the short arm of chromosome 3 in human oral squamous cell carcinomas. Oral Oncol 37: 351-356, 2001

33. Schwarz S, Bier J, Driemel O, et al: Losses of $3 \mathrm{p} 14$ and 9p21 as shown by fluorescence in situ hybridization are early events in tumorigenesis of oral squamous cell carcinoma and already occur in simple keratosis. Cytometry A 73: 305-311, 2008.

34. El-Naggar AK, Hurr K, Batsakis JG, et al: Sequential loss of heterozygosity at microsatellite motifs in preinvasive and invasive head and neck squamous carcinoma. Cancer Res 55: 2656-2659, 1995.

35. Ohta S, Uemura H, Matsui Y, et al: Alterations of p16 and p14ARF genes and their 9p21 locus in oral squamous cell carcinoma. Oral Surg Oral Med Oral Pathol Oral Radiol Endod 107: 81-91, 2009.

36. Gebhart E, Liehr T, Wolff E, et al: Loss of 9p21 is embedded in a complex but consistent pattern of genomic imbalances in oral squamous cell carcinomas. Cytogenet Genome Res 101: 106-112, 2003.

37. Moles MAG, Montoya JAG and Avila IR: Bases moleculares de la cancerización de cavidad oral. Av Odontoestomatol 24: 55-60, 2008.

38. Stephens HA, Vaughan RW, Collins R, et al: Towards a molecular phototyping system for allelic variants of MICA, encoded by polymorphisms in exons 2, 3 and 4 of MHC class I chainrelated genes. Tissue Antigens 53: 167-174, 1999.

39. Costa Ade L, de Araujo NS, Pinto Ddos S and de Araujo VC: PCNA/AgNOR and Ki-67/AgNOR double staining in oral squamous cell carcinoma. J Oral Pathol Med 28: 438-441, 1999.

40. Brandt B, Meyer-Staeckling S, Schmidt H, et al: Mechanisms of EGFR gene transcription modulation: relationship to cancer risk and therapy response. Clin Cancer Res 12: 7252-7260, 2006.

41. Silva SD, Perez DE, Alves FA, et al: ErbB2 and fatty acid synthase (FAS) expression in 102 squamous cell carcinomas of the tongue: correlation with clinical outcomes. Oral Oncol 44: 484-490, 2008.

42. Schartinger VH, Kacani L, Andrle J, et al: Pharmacodiagnostic value of the HER family in head and neck squamous cell carcinoma. ORL J Otorhinolaryngol Relat Spec 66: 21-26, 2004.

43. Vairaktaris E, Goutzanis L, Kalokerinos G, et al: Diabetes increases both $\mathrm{N}$-ras and ets-1 expression during rat oral oncogenesis resulting in enhanced cell proliferation and metastatic potential. In Vivo 21: 615-621, 2007. 
44. Zhou X, Zhang Z, Yang X, et al: Inhibition of cyclin D1 expression by cyclin D1 shRNAs in human oral squamous cell carcinoma cells is associated with increased cisplatin chemosensitivity. Int J Cancer 124: 483-489, 2009.

45. Sathyan KM, Nalinakumari KR, Abraham T and Kannan S: CCND1 polymorphisms (A870G and C1722G) modulate its protein expression and survival in oral carcinoma. Oral Oncol 44: 689-697, 2008.

46. Marsit CJ, Black CC, Posner MR and Kelsey KT: A genotypephenotype examination of cyclin D1 on risk and outcome of squamous cell carcinoma of the head and neck. Clin Cancer Res 14: 2371-2377, 2008.

47. Kozomara RJ, Brankovic-Magic MV, Jovic NR, et al: Prognostic significance of TP53 mutations in oral squamous cell carcinoma with human papilloma virus infection. Int J Biol Markers 22: 252-257, 2007.

48. Kresty LA, Mallery SR, Knobloch TJ, et al: Alterations of p16(INK4a) and p14(ARF) in patients with severe oral epithelial dysplasia. Cancer Res 62: 5295-5300, 2002.

49. Shintani S, Nakahara Y, Mihara M, et al: Inactivation of the p14(ARF), p15(INK4B) and p16(INK4A) genes is a frequent event in human oral squamous cell carcinomas. Oral Oncol 37: 498-504, 2001

50. Van Heerden WF, Swart TJ, Robson B, et al: FHIT RNA and protein expression in oral squamous cell carcinomas. Anticancer Res 21: 2425-2428, 2001.

51. Van Heerden WF, Swart TJ, van Heerden MB, et al: Immunohistochemical evaluation of Fhit protein expression in oral squamous cell carcinomas. J Oral Pathol Med 28: 433-437, 1999.

52. Teresa DB, Neves KA, Neto CB and Fregonezi PA: Computerassisted analysis of cell proliferation markers in oral lesions. Acta Histochem 109: 377-387, 2007.

53. Schwartz JL, Gu X, Kittles RA, et al: Experimental oral carcinoma of the tongue and buccal mucosa: possible biologic markers linked to cancers at two anatomic sites. Oral Oncol 36: $225-235,2000$.
54. Otero-Rey EM, Somoza-Martin M, Barros-Angueira F and Garcia-Garcia A: Intracellular $\mathrm{pH}$ regulation in oral squamous cell carcinoma is mediated by increased V-ATPase activity via over-expression of the ATP6V1C1 gene. Oral Oncol 44: 193-199, 2008.

55. Imai T, Toyota M, Suzuki $\mathrm{H}$, et al: Epigenetic inactivation of RASSF2 in oral squamous cell carcinoma. Cancer Sci 99: 958-966, 2008.

56. Sudbo J: Novel management of oral cancer: a paradigm of predictive oncology. Clin Med Res 2: 233-242, 2004.

57. Fong D, Spizzo G, Gostner JM, et al: TROP2: a novel prognostic marker in squamous cell carcinoma of the oral cavity. Mod Pathol 21: 186-191, 2008.

58. Mullis TC, Tang X and Chong KT: Expression of connective tissue growth factor (CTGF/CCN2) in head and neck squamous cell carcinoma. J Clin Pathol 61: 606-610, 2008.

59. Kumar SV, Hurteau GJ and Spivack SD: Validity of messenger RNA expression analyses of human saliva. Clin Cancer Res 12: 5033-5039, 2006.

60. Zhong LP, Zhu HG, Zhang CP, et al: Detection of serum Cyfra 21-1 in patients with primary oral squamous cell carcinoma. Int J Oral Maxillofac Surg 36: 230-234, 2007.

61. Zhong LP, Zhang CP, Zheng JW, et al: Increased Cyfra 21-1 concentration in saliva from primary oral squamous cell carcinoma patients. Arch Oral Biol 52: 1079-1087, 2007.

62. Bahar G, Feinmesser R, Shpitzer T, et al: Salivary analysis in oral cancer patients: DNA and protein oxidation, reactive nitrogen species, and antioxidant profile. Cancer 109: 54-59, 2007.

63. Landesberg R, Woo V, Huang L, et al: The expression of the receptor for glycation endproducts (RAGE) in oral squamous cell carcinomas. Oral Surg Oral Med Oral Patho Oral Radiol Endod 105: 617-624, 2008.

64. Epstein JB, Zhang L and Rosin M: Advances in the diagnosis of oral premalignant and malignant lesions. J Can Dent Assoc 68: $617-621,2002$. 